\title{
Patient adherence to ischemic heart disease treatment
}

\author{
Moacyr Roberto Cuce Nobre ${ }^{1 *}$, Rachel Zanetta de Lima Domingues ${ }^{2}$ \\ ${ }^{1}$ Director of the Clinical Epidemiology and Research Support Team - Heart Institute (InCor), Hospital das Clínicas da Faculdade de Medicina da Universidade de São Paulo (HC-FMUSP), São Paulo, SP, Brazil \\ ${ }^{2}$ Consultant at Cognos - Health Education. Collaborator for the Clinical Epidemiology and Research Support Team, InCor-HC-FMUSP, São Paulo, SP, Brazil
}

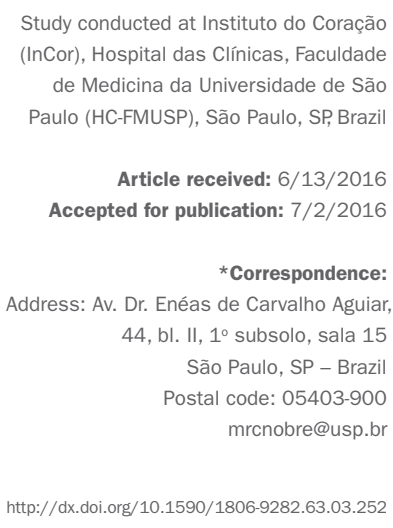

\section{SUMMARY}

Introduction: The effectiveness of the treatment of chronic diseases depends on the participation of the patient, influenced by different sociocultural factors, which are not fully recognized by the treatment routine.

Objective: To search for some of these factors that hinder or facilitate adherence to treatment and use of healthcare resources, approaching patients with ischemic heart disease.

Method: A cross-sectional study was conducted using face-to-face interviews. We applied semi-structured questionnaires to 347 individuals and recorded 141 interviews for qualitative analysis. Descriptors were selected to identify eight categories of analyses. The quantitative data were submitted to descriptive analysis of frequency. Results: Only 2\% had good medication adherence according to score on Morisky questionnaire. About $23 \%$ bought statins; the others obtained statin in the public health institution. Thirty-six speeches were selected and classified according to the following categories: knowledge about disease and medication, difficulty of acquisition, self management of treatment, difficulties of access to health services, side effect of statins, caregiver support, transportation to health services and concerns about the disease progression. However, it was noticed that about $1 / 3$ of the care outside the research institution can be characterized as an attempt to bring rationalization to the health system.

Conclusion: The improved adherence to chronic treatment of ischemic heart disease depends on the establishment of effective flows for referral and counter-referral from one care unit to another, relevant information and clarification of the questions for the patients and the attention of health professionals to the many social and cultural factors involved in treatment adherence. New research should be focused on educational groups by integrated multidisciplinary teams in order to share treatment decisions, thereby increasing the patient's commitment to his own health.

Keywords: medication adherence, patient compliance, qualitative research, myocardial ischemia, health service.

\section{INTRODUCTION}

Adherence to medication is defined as the degree to which the patient is in accordance with the interval and dose regimen prescribed. Adherence and persistence to medication are two different constructs. Adherence to medication refers to the degree or extent of compliance to the health care provider's recommendations for day-to-day treatment. Persistence is defined as the period of time of use from its onset to the eventual discontinuation of treatment. ${ }^{1-2}$

Adherence to medication is defined by the World Health Organization as the degree to which a person's behavior matches the recommendations agreed upon with the health team. Although adherence is synonymous with compliance, the latter is adopted to identify the patient's behavior that corresponds to the prescribed treatment, without any change. Adherence, however, means that patient and physician collaborate in the search for health improvement by integrating their conduct, taking into account factors such as patient lifestyle, values and preferences. ${ }^{3}$

This subject has been discussed for decades ${ }^{4}$ and there is still much to study in face of discontinuation and low adherence observed among patients with chronic diseases. ${ }^{5}$ 
Facing the innumerable associated factors, the main barriers identified by self-report of patients can be summarized as: perception of the harm caused by the drug compared to the benefits, the actual need for medication, and the cost of medication when payment is made by patients. ${ }^{6}$

In a similar study carried out in this same institution and published in 1996, in which the conformity assessment was based on the comparison of the patient's response with the annotations in the medical records and prescription form, noncompliance occurred in 59\% of the cases. Difficulties reported in taking the medication included side effects, cost, neglect, rejection, improvement of symptoms, drug unavailable in the market and inability to identify the names of medications. These were the main predictors of nonconformity. ${ }^{7}$ Low adherence is also associated with lower income of the respondent and a lack of professional commitment to explain the disease and medication. ${ }^{8}$

There is the recurring idea that the physician can be exempted from responsibility for the health consequences of the patient who decides autonomously not to follow the treatment as indicated, as if the patient had a submissive role following recommendations. ${ }^{9}$ On the other hand, there are also proposals for training health professionals to qualify them to listen and talk with the patient, and then share treatment decisions with them. ${ }^{10}$ Treatment and follow-up of hypertensive and diabetic patients through group-led educational activities, associated to the provision of medication and care of intercurrences by a multidisciplinary team, in a period of 30 months, showed to be effective to improve the control of these diseases. ${ }^{11}$

Tertiary hospitals of greater technological complexity dedicated to university education, such as the institution where this research was carried out, serve people with very heterogeneous health-related values. This is due to the cultural miscegenation found in large cities, strengthened by a distant place of dwelling that extends to other regions of the state, the country or even abroad. Such cultural diversity leads to different forms of understanding the disease and its treatment, as well as the adaptations that people who are ill seek to make in their daily routines. All of these factors may directly interfere with the quality of treatment adherence.

From our point of view, many of these diversities are not recognized by the institutional routine, justifying the proposal of this research to know the factors associated with adherence to drug treatment.

\section{Objective}

To identify the factors hindering or facilitating treatment adherence and the use of care resources by patients with ischemic heart disease.

\section{Method}

Cross-sectional study involving the application of an instrument with open and closed questions through face-to-face and individual interviews, in which patients are approached by the researchers only once.

The population cared for at InCor derives from three different sources: the Brazilian Public Health System (SUS, in the Portuguese acronym), supplementary plan, and private health insurance. About $80 \%$ of the Institute's global care is provided to patients with funding from the SUS. All patients benefit from the same standard of excellence in cardiology and pulmonology for which the Institute is recognized internationally, from prevention to treatment of the most complex pathologies in these specialties. The survey did not take into account how patients are individually characterized according to their socioeconomic position. The interviews showed that patients with different social and economic features use public resources financed by the SUS. The study included adults diagnosed with ischemic heart disease as defined by the International Code of Diseases, version 10 (ICD-10) codes I20, I21, I22, $\mathrm{I} 23, \mathrm{I} 24$ and I25, regularly enrolled in the institution between January 1, 2000 and December 31, 2010, with return appointments scheduled from August 1 to December 18, 2014. On the day before the consultation, attempts were made to contact the patients by telephone to arrange the interview. Patients who were unable to be interviewed due to cognitive impairment were excluded. The list of patients was obtained from the Institution's Medical-Hospital Information Unit.

The instrument for collecting data on drug adherence was the Morisky questionnaire, composed of four questions. ${ }^{12}$ As a complement, 20 open and closed questions were elaborated to identify possible changes in the place of care in the period between scheduled appointments, medication acquisition regardless of whether they were provided by the institution, identification of the drugs in the statins group, and how the patient rates communication with the professionals that provide the institutional care. The interviews were conducted by two previously trained researchers. The interviews were recorded after the patients signed a Term of Free and Informed Consent approved by the CAPPesq ethics and research committee under number 742.267 on August 6, 2014.

All interviews were analyzed by a single researcher who extracted the qualitative data by analysis category. ${ }^{13}$ Categories in Table 1 were selected based on the position on the keywords of each question asked, considering the theoretical reference on adherence, raised for the construction of the questionnaire. We selected the statements that best represented the context of each category to represent the analyzed group. ${ }^{14,15}$ The categories were as follows: I 
TABLE 1 Categories defined on the basis of language, examples taken from interviews recorded with patients.

\begin{tabular}{|c|c|c|}
\hline I & $\begin{array}{l}\text { Knowledge about } \\
\text { the medication }\end{array}$ & $\begin{array}{l}\text { "The first gave me a lot of pain in my leg, I couldn't even stand up. I said to my son that the pain was killing } \\
\text { me, and then, later, the doctor explained it all." }\end{array}$ \\
\hline II & $\begin{array}{l}\text { Difficulty to acquire } \\
\text { the medication }\end{array}$ & $\begin{array}{l}\text { "The bad thing is that the pharmacy doesn't have all the medicines and I can't always buy them, then I end up } \\
\text { without my medication until they receive more. I keep calling and asking please, but they do not always send } \\
\text { all medications. The ones I know that are always missing, I take half to try to make it last longer." }\end{array}$ \\
\hline III & $\begin{array}{l}\text { Global management of the } \\
\text { treatment }\end{array}$ & $\begin{array}{l}\text { "Look at the prescription, I don't know if I take it, it's a lot of medicine and sometimes the pharmacy gives } \\
\text { another one." }\end{array}$ \\
\hline IV & Access to health services & $\begin{array}{l}\text { "I've never had a problem getting the pills. Before I had to come here, now it's better, they send it to my house, } \\
\text { which is near here. I don't like to make an appointment because it's always full, we sometimes go back to the } \\
\text { doctor's office without the exams. Then the doctor gets angry and says that we did not insist, but this is not } \\
\text { true. There is always medication, I mean statins, but sometimes other drugs are missing." }\end{array}$ \\
\hline V & Side effects of the drug & $\begin{array}{l}\text { "I'm not going to lie, I have to say the truth. Sometimes, I stop taking it because I get too tired, it's because } \\
\text { there is not enough fat in my body. Then I stop it for about ten days, and feel better again." }\end{array}$ \\
\hline VI & Caregiver support & $\begin{array}{l}\text { "When my daughter comes, it is easy, because she makes the doctor answer the doubts, everything is explained. } \\
\text { But if she can't come, it all becomes a mess, because I do not know if I am getting better or worse, I get confused." }\end{array}$ \\
\hline VII & Transport to health services & "I live a long way from here and it's very hard to come, so I got a health insurance to follow me closely." \\
\hline VIII & $\begin{array}{l}\text { Be afraid of disease } \\
\text { progression }\end{array}$ & $\begin{array}{l}\text { "I was always afraid to die until the first heart attack. Then I've lost my fear. It's ugly, like a rag entering your } \\
\text { throat, you want to do something, but you can't, so I do everything the doctor says." }\end{array}$ \\
\hline
\end{tabular}

- Knowledge about the medication; II - Difficulty to acquire the medication; III - Global management of the treatment; IV - Access to health services; $\mathrm{V}$ - Side effects of the drug; VI - Caregiver support; VII - Transport to health services; VIII - Concerns regarding health evolution. Qualitative analysis was done on the basis of correlation to identify the keywords associated with the drug, personal and institutional factors. The purpose of our analysis was to summarize the motives and representations of the context where individuals are inserted in the answers obtained when asked about the different aspects that identify them in the adherence to the proposed treatment. ${ }^{16}$

Adherence was assessed as a whole for the drugs used, complemented with specific questions regarding statin use. In the recorded interviews, whenever possible, the types of statins used were transcribed.

Quantitative data were entered in Excel spreadsheet for descriptive analysis of frequencies. Qualitative and quantitative results are presented together for each item of the questionnaire.

The transcripts of part of the patient's statements, selected according to the pre-established keywords, are presented using "quotation marks," together with the related quantitative data, shown in italics, followed by the discussion of these data with the relevant literature.

The patients' statements were transcribed as closely as possible to the recorded content. Very few modifications were made, to preserve proper Portuguese grammar, and to help the reader identify the places referred to, when us- ing expressions such as "I was treated at the hospital which is just in front of this one."

\section{Results ANd Discussion}

We contacted 2,191 individuals within 16 weeks, of which 347 were submitted to closed questionnaires for analysis of quantitative data, and 141 of the interviews were recorded for qualitative analysis.

Whether the patients accepted or not to participate in the interview depended on the time of the consultation, room availability, their availability of time to remain in the institution, orientation to move within the physical space destined to assistance and research, participation in other concomitant surveys, and whether they were present or missed the scheduled appointment.

Thirty-six statements were selected according to the following categories: five in category I - Knowledge about the medication; six in category II - Difficulty to acquire the medication; three in category III - Global management of the treatment; 14 in category IV - Access to health services; four in category $\mathrm{V}$ - Side effects of the drug; two in category VI - Caregiver support; one in category VII - Transport to health services; one in category VIII - Concerns regarding health evolution. Four statements were placed into more than one category. In the statements selected, the predominance of difficulties or disorganization of access to health services was clear.

According to Morisky's classification, with four questions, adherence to cardiovascular drugs among 347 re- 
spondents was considered low in $47(13.5 \%)$, moderate in 292 (84.1\%) and high in only eight of the respondents (2.3\%).

"I saw on the television that two glasses of green juice would help control my blood pressure, then I started to drink it instead of taking the medicine in the morning, which made me very dizzy." Category $\mathrm{V}$

"It is always easier when my grandson can accompany me. Later, he writes everything down and posts it on the refrigerator door with the schedules. There are 17 pills every day, I think.” Category III

Factors that cause individuals to fail to follow proper medical guidance may be related to illiteracy, alcoholism, unemployment, delayed improvement of symptoms, and lack of treatment supervision due to excessive delay between visits. ${ }^{17}$ Also lack of understanding about the chronic nature of the disease, medication side effects, influence of the media, search for alternative treatments, absence of a caregiver, lack of empathy with the health team due to constant change of professionals, conflicts due to care received in different services. ${ }^{18}$ Understanding of illness is also associated with the health condition as perceived within normality, life expectancies, including previous experiences, understanding the different meanings of health according to the social group to which the individual belongs. ${ }^{19}$

"The consultations are far, so I bought a health plan so that I can go there when I have something, but do the follow up closer." Category VII

"The problem is that I come with my daughter-in-law and she does not have time to extend our visit to the service's pharmacy because it takes too long from the time we arrive for consultation to us leaving with the medicine, so I try at the community health clinic. But the community health clinic does not always have what was prescribed here." Category IV + VI

"When my daughter comes, it is easy, because she makes the doctor answer the doubts, everything is explained. But if she can't come, it all becomes a mess, because I do not know if I am getting better or worse, I get confused.” Category VI

Low adherence caused by difficulty in solving doubts due to the low availability of health professionals to listen, concerns related to the medication received leading to reduction in the appropriate dose, need to schedule an appointment to renew a prescription and acquisition of the drug in other places. The nature, meaning and determinants of low adherence behavior are complex and difficult to understand. The subjectivity of the responses and the needs and difficulties of each patient should be considered before assessing the precision with which they follow the recommendations. ${ }^{9}$

"If the doctors were the same, things would be better, but they usually change. And there are some who do not listen, they just write and give us the prescription and the exams to return in 1 year. This makes things harder, because we have no time to speak about the medication." Category IV

"I always take the medication. Sometimes, I forget to take it at the right time, but then I take it as soon as I remember. Never miss a day; I actually take the medicine after a few hours." Category III

Current statin use was observed in 342 respondents (98.6\%). Seventy percent (245/331) have taken statins for five or more years.

Another study conducted in Brazil showed that, of those who were prescribed statins, only $41 \%$ used the drug. Among non-adherents, $2 / 3$ did not take the drug due to cost issues, $1 / 3$ for lack of guidance or lack of medication, and $2 \%$ due to adverse effects. ${ }^{20}$

“Look at the prescription, I don't know if I take it, it's a lot of medicine and sometimes the pharmacy gives me a different one." Category III

"I think everything is fine. The bad thing is that the pharmacy doesn't have all the medicines and I can't always buy them, then I end up without my medication until they receive more. I keep calling and asking please, but they do not always send all medications. The ones I know that are always missing, I take half of what was recommended to try to make it last longer." Category II

Decisions taken in the daily routine may not fit the guidelines received for treatment, even if such provision exists. Understanding the effects of medication was reported as an important factor for adherence.

"The first statin gave me a lot of pain in my leg, I couldn't even stand up. I said to my son: the pain is killing me. Later, the doctor explained it all." Category I + V

"I felt very tired when I began taking the statin, I resisted for 2 months and looked for the doctor. He changed the 
type of medication and then explained: it is not good, but it is medication, you have to take it." Category I + V

"The doctor explained that I have a sick heart and said: if you follow the treatment, take the medicines right, come in the appointments and follow the directions given here in the hospital, you will live better. If you take the medicine from time to time, and do not follow the directions, I can't say that you will die sooner, but I say for sure that you will live worse, feel bad more often, and it will be harder. Medication is now part of everything you do every day, like eating, you have to eat every day, you have to take the medicine every day. That's why I do not stop taking it, I understood, because I tested it and it's true." Category I

Systematic review has concluded that, since the first consultation, it is the responsibility of the professional to inform about the illness and treatment realistically, taking as counterpoint the risk of the disease. ${ }^{21} \mathrm{~A}$ cohort followed for four years in Denmark defines adherence as a proportion of days covered with medication above $80 \%$, or with use gap of at least 365 continuous days. Higher adherence was observed among women and individuals with higher education. Statin adherence was lower among men with lower income. ${ }^{22}$

The vast majority of respondents, $88.5 \%$ (307/347), said that they get statin at the hospital pharmacy or receive it at home.

"I've never had a problem getting the pills. Before, I had to come here, now it's better, they send it to my house, which is near here. I don't like to make an appointment because it's always full; we sometimes go back to the doctor's office without the exams. Then the doctor gets angry and says that we did not insist, but this is not true. There is always medication, I mean statins, but sometimes other drugs are missing." Category IV

The difficulty in scheduling can have negative consequences on the outcome of treatment, even if adherence is high. An Australian study linked national reimbursement data for prescribing statins to non-adherence factors, with $80 \%$ of patients in two years and $57 \%$ in four. The measures were higher in the less healthy elderly, with lower self-perception of health, preexisting heart disease, obese, smokers, those with private health insurance, difficulties in understanding the English language and those who reported greater psychological distress. There was no correlation with income or with the place of residence. ${ }^{23}$
Despite the availability of statins in the pharmacy of the health institution, the drug was bought from commercial pharmacies by 83 (23.9\%) of the 347 respondents, and bought as complement in the primary SUS network by 70 respondents $(20.2 \%)$. "My neighbor's husband takes the same medicine and some-
times she gives it to me, my employer also buys it for me.
She knows I can't afford it." Category II

"I would pick it up here, and then I started to receive it at home. It was good and bad, because if there is no one at home they do not come back, nor do they leave the medicine with the neighbor or in front of the door. Today, I am going to ask if I can get the medication here, it is better." Category II

Among those interviewed, 94.8\% always get the medication from the same source; however, they report difficulty in acquiring it from other places, failing to take it when they cannot change their prescription or even when they have doubts concerning the name of the drug being changed in the pharmacy or in another service unit.

\footnotetext{
"I receive my medicine at home almost always, but sometimes it is missing. Then, I have to do my best to try to find it elsewhere or borrow money to buy it. Sometimes, the community health clinic changes it for something similar, because the drug that was prescribed is missing. What can we do? Better than nothing." Category II
}

"The bad thing about getting the medication from the community health clinic is that we have to change the prescription. Sometimes, there are no drugs, then we have to find another community health clinic. Whenever I don't feel like going from one pharmacy to another, I go days or weeks without medication. This is if my medical appointment is not scheduled for three months later." Category II + IV

Atorvastatin was indicated for $68.6 \%$ of patients, who report changes during treatment. Other patients misuse it because they do not know the medication.

"I was first treated with atorvastatin, prescribed by the doctor here, and he asked me to go to the community health clinic for monitoring. There, another doctor gave me simvastatin. I take two, in the morning and in the evening." Category I

Failure to adhere may result from lack of information or even from different presentations of the same medication. 
Professionals tend to approach adherence under their own perspectives, ignoring those of the patient, questioning the legitimacy of their behavior. They judge and label the patient, rather than knowing and understanding them. ${ }^{24}$

Of 347 patients, 238 (68.6\%) reported the use of atorvastatin, $214(61.7 \%)$ simvastatin, six $(1.7 \%)$ rosuvastatin and $41(11.8 \%)$ other drugs.

"I started with rosuvastatin and then the doctor switched to simvastatin, which is provided by the public health network." Category IV

Adherence to the rehabilitation program and drug use depend on the individual information needs. ${ }^{25}$ Clarifications and belief in the benefit of treatment also assist in the treatment, ${ }^{26}$ as well as the patient's assessment of their health status. ${ }^{27}$

Among the 347 respondents, 57 (16.4\%) discontinued the use of statin at some point for a longer time.

"I'm not going to lie. I have to say the truth. Sometimes I stop taking it because I get too tired, I feel like there is not enough fat in my body. Then I stop it for about ten days, and feel better again.” Category $\mathrm{V}$

In the information exchanged in conversation with other patients, statin is considered a reducer of blood or cholesterol fat, but there is no comment on the possible side effects of the drug.

"I take less as soon as I realize that I won't have enough. Then I take less, stop for a while, so that I'll have enough.” Category II

Irregularity in the delivery of medication leads to inadequate solutions, not discussed with the care team.

Of the 57 patients who discontinued the medication, $57.9 \%$ did so on their own, $29.8 \%$ under medical advice and $12.3 \%$ for unidentified reasons.

"The prescription read a name, then the pharmacy said that they didn't have it with that exact name but they would give me another with a different name that was the same thing. Then, I got confused, I took it for a week but my son said: if you think it's not right, don't take it.” Category I

It has been observed in patients with coronary disease that adherence to the drug has decreased over time, and that prescription at hospital discharge may increase the likelihood of adherence among elderly patients. ${ }^{28}$
Of the 57 patients reporting the reason for stopping the drug, 27 (47.4\%) reported that the drug was not available at the institution's pharmacy. Among the other 30 patients, six (20\%) reported that the drug was not available at the Basic Health Unit near their homes, four (13\%) felt discomfort with the medication, two (6.5\%) reported clinical improvement, two (6.5\%) wanted to take a break from the drug and 16 (53.0\%) gave other reasons.

New qualitative studies are needed to clarify the reasons for the voluntary suspension of the drug, such as the presence of more than one patient in the home who uses medications, or conflicts resulting from the orientation received in different places of care.

Occasional lack of symptoms may underestimate the severity of the disease, with the patient having to adapt to chronic illness after the sudden onset of myocardial infarction. Also, the patient may have to face negative beliefs about medications, and control the resulting anxiety. The attending physician should adopt an open approach with a flexible posture and accessible language, so that more effective communication facilitates patient adherence to treatment. ${ }^{21}$

Among the 57 patients who stopped using statin, 19 (33.3\%) did so for up to one month, 17 (29.8\%) for more than one month and up to one year, four $(7.0 \%)$ stopped for more than one year and 17 (29.8\%) did not know the time.

Muscular pain or other side effect was the main predictor cited for statin cessation in $60 \%$ of patients, while $16 \%$ cited cost and $13 \%$ cited perception of lack of effect. Patients who stopped using the drug also reported low satisfaction with their doctors, poor understanding of treatment, more internet access for information and less frequent monitoring of cholesterol levels. ${ }^{29}$

Among those who reported never having stopped taking the medicines, the report of a patient who had great fear of the disease progression after experiencing an acute ischemic event stands out.

"I was always afraid to die until the first heart attack. Then I've lost my fear. It's ugly, like a rag entering your throat, you want to do something, but you can't, so I do everything the doctor says." Category VIII

Of 347 patients, 179 (49.0\%) sought another place of care, in addition to the place where this research was conducted.

"I am treated here and at the hospital in São Bernardo, because the doctor here referred me for monitoring there, but it was doctor X. The other doctor said that I should 
stay here, because I am also being treated at the building in the front, the one for diabetes and skin diseases, and that's where they told me to stay here. I have an appointment here today and I'll ask the doctor what to do, since the other doctor said that I should be treated at the other hospital." Category IV

"I could not have my exams scheduled here, it was taking too long. I came back to see the doctor without any results. The doctor got mad and sent me to another hospital to have the exams done." Category IV

Despite the long wait to reschedule an appointment at the institution, which was mentioned in the interviews as a reason to be treated elsewhere, the frequency of that could not be quantified. Nevertheless, of the 170 patients who sought other institutions for health care, 107 (62.9\%) gave as reason the presence of other diseases, 54 (34.7\%) do so routinely combined with the care provided at the institution and four (2.4\%) did it for catheterization.

"I get the medication from the Basic Health Unit close to my home. Every month, the nurse measures my pressure, and every six months I go to the doctor. Here, the consultation is done annually, not to mention that the Unit is closer." Category IV

"I treat prostate cancer somewhere else, but the heart just here. I mean, the doctor there asks for the exams and if there's something wrong he asks to go to the cardiologist there, but the doctor from there only modifies the dose of the medicine and says it's to talk to the doctor here." Category IV

"They sent me from here to have the exams done there. There are too many patients here and I have health insurance, so I told the doctor and he said okay.” Category IV

"When I need it, I use the private service because rescheduling here is impossible. They say they have no vacancy, and it is not always a case of emergency room. It's hard because the doctors say different things." Category IV

The authors interpret these last statements as characteristic of an attempt to rationalize the network, which is not always successful, by providers and users, especially by patients residing outside the Municipalities of the Greater São Paulo Area.

The 170 patients who sought other care were divided into primary (35.9\%), secondary (32.9\%) and tertiary (31.2\%). The two main reasons cited for this spontaneous demand were: proximity to their homes or because they were taken in an emergency situation.

Hospitalization at another institution has been reported in cases of emergency or other non-cardiovascular causes. About $43 \%$ of the patients report having been hospitalized for more than two days. Those who reported longer time justified it with complications in performing exams, or because they underwent extensive surgeries. This data could not be quantified, remaining as an observation of the researchers.

"I felt a strong pain, I had been here at the doctor and he changed my medicine, I thought that was it, and I took a break. The pain stopped, but after 2 days I fainted, my son took me to the hospital near our house, and I stayed there for 15 days." Category IV

Of 149 patients, $42.9 \%$ of the total interviewed with hospital admission, 85 (57.0\%) reported being hospitalized only in the institution, while 13 (8.7\%) had hospitalizations in this and other institutions. Out of the 347 participants, 271 (78.1\%) had a heart attack. The number of times they had a heart attack was reported as one time by 148 patients (54.6\%), twice by 63 patients $(23.2 \%)$, three times by 18 (7.4\%), four or more times by 18 (7.4\%), and 24 of the respondents $(8.9 \%)$ did not respond.

\footnotetext{
"They said only five heart attacks (laughing), but I don't believe it. I felt sick only once, they called an ambulance that took me to the Teaching Hospital at USP. After that, I came here. I stayed seven days at the ER, then back to USP. I'm being treated at both places." Category IV
}

As for the place used to treat events with a greater degree of complexity: 110 of 271 patients (40.6\%) reported using other resources outside the institution to treat acute myocardial infarction. Out of 347 respondents, 143 (41.2\%) underwent myocardial revascularization surgery, and 42 of 139 surgically treated patients (30.2\%) used other hospitals. Percutaneous angioplasty was performed in 178 of 347 respondents $(51.3 \%)$, and 51 of 178 patients $(28.7 \%)$ used other hospitals.

"When I come here, I know that the whole day is taken. But what can I do? I can't complain." Category IV

There is a need to invest in care programs for those with chronic health problems so that education is privileged and that the different needs of both the patients and their families are met, involving health care professionals and 
government institutions. It is unlikely that any intervention that ignores the multidimensionality of problems will succeed in achieving behavior change. ${ }^{30}$

\section{Conclusion}

In the statements selected, the predominance of difficulties or disorganization in the access to health services was clear. Also important were the lack of knowledge about the treatment, difficulty in acquiring medication and the occurrence of side effects of statins. However, it was noticed that about $1 / 3$ of the medical care away from the institution can be characterized as an attempt to rationalize the network.

Improvement in adherence to chronic treatment of ischemic heart disease depends on the establishment of effective referral and counter-referral flows among care units, as well as adequate information and clarification of patient's doubts, attention of health professionals to multiple social and cultural factors that are involved with adherence to treatment.

Further research is needed on the role of pharmaceutical care, educational groups, and the integration of multiprofessional teams to engage the patient to share treatment decisions, thus enhancing commitment to their own health.

\section{AcKNoWLeDGMENTS}

We thank Mr. Marcio Polydoro for his contribution in scheduling the interviews and collecting the data.

\section{Conflict of interest}

The authors declare no conflict of interest.

\section{Resumo}

Adesão do paciente ao tratamento da doença isquêmica do coração

Introdução: A efetividade do tratamento das doenças crônicas depende da participação do paciente, influenciada por diferentes motivos socioculturais, pouco reconhecidos pela rotina assistencial.

Objetivo: Identificar os fatores de adesão ao tratamento e o uso dos recursos assistenciais de pacientes com doença isquêmica do coração.

Método: Estudo transversal com entrevistas presenciais de 347 indivíduos submetidos a questionários semiestruturados, com 141 delas gravadas para análise qualitativa com identificação dos descritores distribuídos por oito categorias. Os dados quantitativos tiveram análise descritiva de frequência.
Resultados: Somente $2 \%$ tiveram boa adesão medicamentosa; $23 \%$ compraram estatina, os demais obtiveram o medicamento em serviços públicos. Foram classificadas 36 falas com as categorias: conhecimento sobre a doença e o tratamento, dificuldade de aquisição do medicamento, gerenciamento pessoal do tratamento, acesso aos serviços de saúde, efeito colateral das estatinas, apoio do cuidador, transporte até o ambulatório, receios quanto à evolução da doença, efeito colateral das estatinas. Foi observado que $1 / 3$ dos atendimentos fora da instituição podem ser caracterizados como tentativa de racionalização da rede. Conclusão: A melhora da adesão ao tratamento da doença isquêmica do coração depende do estabelecimento de fluxos efetivos para referência e contrarreferência entre unidades assistenciais; adequada informação e esclarecimento das dúvidas do paciente; atenção dos profissionais de saúde aos múltiplos fatores sociais e culturais envolvidos com a adesão. São necessários novos estudos sobre o papel da assistência farmacêutica, grupos educativos e integração da equipe multiprofissional no engajamento do paciente para compartilhar as decisões sobre o tratamento, e assim ampliar seu grau de comprometimento com a própria saúde.

Palavras-chave: adesão ao medicamento, cooperação do paciente, pesquisa qualitativa, isquemia miocárdica e serviços de saúde.

\section{References}

1. Cramer JA, Roy A, Burrell A, Fairchild CJ, Fuldeore MJ, Ollendorf DA, et al Medication compliance and persistence: terminology and definitions. Value Health. 2008; 11(1):44-7.

2. Vermeire E, Hearnshaw H, Van Royen P, Denekens J. Patient adherence to treatment: three decades of research. A comprehensive review. J Clin Pharm Ther. 2001; 26(5):331-42.

3. Jimmy B, Jimmy J. Patient medication adherence: measures in daily practice. Oman Med J. 2011; 26(3):155-9.

4. Sackett DL, Haynes RB, Gibson ES, Hackett BC, Taylor DW, Roberts RS, et al. Randomised clinical trial of strategies for improving medication compliance in primary hypertension. Lancet. 1975; 1(7918):1205-7.

5. Gwadry-Sridhar FH, Manias E, Lal L, Salas M, Hughes DA, Ratzki-Leewing A, et al. Impact of interventions on medication adherence and blood pressure control in patients with essential hypertension: a systematic review by the ISPOR medication adherence and persistence special interest group. Value Health. 2013; 16(5):863-71.

6. McHorney CA. The Adherence Estimator: a brief, proximal screener for patient propensity to adhere to prescription medications for chronic disease. Curr Med Res Opin. 2009; 25(1):215-38.

7. Chizzola PR, Mansur AJ, da Luz PL, Bellotti G. Compliance with pharmacological treatment in outpatients from a Brazilian cardiology referral center. Sao Paulo Med J. 1996; 114(5):1259-64.

8. Simon-Tuval T, Triki N, Chodick G, Greenberg D. Determinants of costrelated nonadherence to medications among chronically ill patients in Maccabi Healthcare Services, Israel. Value Health Reg Issues. 2014; 4:41-6.

9. Reiners AAO, Azevedo RCS, Vieira MA, Arruda ALG. Produção bibliográfica sobre adesão/não-adesão de pessoas ao tratamento de saúde. Ciênc Saúde Coletiva. 2008; 13(suppl. 2):2299-306.

10. Giguere AM, Labrecque M, Légaré F, Grad R, Cauchon M, Greenway M, et al. Feasibility of a randomized controlled trial to evaluate the impact of 
decision boxes on shared decision-making processes. BMC Med Inform Decis Mak. 2015; 15:13.

11. Silva TR, Feldman C, Lima MHA, Nobre MRC, Domingues RZL. Controle de diabetes mellitus e hipertensão arterial com grupos de intervenção educacional e terapêutica em seguimento ambulatorial de uma Unidade Básica de Saúde. Saúde Soc. 2006; 15(3):180-9.

12. Morisky DE, Green LW, Levine DM. Concurrent and predictive validity of a self-reported measure of medication adherence. Med Care. 1986; 24(1):67-74.

13. Patton MQ. Qualitative evaluation methods. Beverly Hills: Sage; 1980.

14. Badin A. Análise de conteúdo. Lisboa: Edições 70; 2004.

15. Minayo MCS. O desafio do conhecimento: pesquisa qualitativa em saúde. São Paulo/Rio de Janeiro: Hucitec/Abrasco; 2004.

16. Ulin PR, Robinson ET, Tolley EE. Qualitative methods in Public Health: field guide for applied research. San Francisco; California: Jossey-Bass; 2004.

17. Lopes RH, Menezes RMP, Costa TD, Queiroz AAR, Cirino ID, Garcia MCC. Fatores associados ao abandono do tratamento da tuberculose pulmonar: Uma revisão integrativa. Rev Baiana Saúde Pública. 2013; 37(3):661-71.

18. Mauskop A, Borden WB. Predictors of statin adherence. Curr Cardiol Rep. 2011; 13(6):553-8

19. Gomes R, Mendonça EA, Pontes ML. As representações sociais e a experiência da doença. Cad Saúde Pública. 2002; 18(5):1207-14.

20. Mansur AP, Mattar AP, Tsubo CE, Simão DT, Yoshi FR, Daci K. Prescription and adherence to statins of patients with coronary artery disease and hypercholesterolemia. Arq Bras Cardiol. 2001; 76(2):111-8.

21. Rashid MA, Edwards D, Walter FM, Mant J. Medication taking in coronary artery disease: a systematic review and qualitative synthesis. Ann Fam Med. 2014; $12(3): 224-32$.
22. Wallach-Kildemoes H, Andersen M, Diderichsen F, Lange T. Adherence to preventive statin therapy according to socioeconomic position. Eur J Clin Pharmacol. 2013; 69(8):1553-63.

23. Warren JR, Falster MO, Fox D, Jorm L. Factors influencing adherence in long-term use of statins. Pharmacoepidemiol Drug Saf. 2013; 22(12):1298-307.

24. Trostle JA. Medical compliance as an ideology. Soc Sci Med. 1988; 27(12):1299-308.

25. White S, Bissell P, Anderson C. Patients' perspectives on cardiac rehabilitation, lifestyle change and taking medicines: implications for service development. J Health Serv Res Policy. 2010; 15(Suppl 2):47-53.

26. Tolmie EP, Lindsay GM, Kerr SM, Brown MR, Ford I, Gaw A. Patients perspectives on statin therapy for treatment of hypercholesterolaemia: a qualitative study. Eur J Cardiovasc Nurs. 2003; 2(2):141-9.

27. Elliott RA, Shinogle JA, Peele P, Bhosle M, Hughes DA. Understanding medication compliance and persistence from an economics perspective. Value Health. 2008; 11(4):600-10.

28. Ivers NM, Schwalm JD, Jackevicius CA, Guo H, Tu JV, Natarajan M. Length of initial prescription at hospital discharge and long-term medication adherence for elderly patients with coronary artery disease: a populationlevel study. Can J Cardiol. 2013; 29(11):1408-14.

29. Wei MY, Ito MK, Cohen JD, Brinton EA, Jacobson TA. Predictors of statin adherence, switching, and discontinuation in the USAGE survey: understanding the use of statins in America and gaps in patient education. J Clin Lipidol. 2013; 7(5):472-83.

30. Becker MH, Maiman LA. Strategies for enhancing patient compliance. J Community Health. 1980; 6(2):113-35 